\title{
PROTECTIVE EFFECT OF RESVERATROL AGAINST CORTICOSTERONE-INDUCED NEUROTOXICITY IN PC12 CELLS
}

Abstract

Objective: Resveratrol(RES) is a natural polyphenol which possesses an anti-depressant effect. However, the mechanisms of its anti-depressant effect remain unclear. The aim of the study is to investigate the potential mechanisms in the neuro-protective efficiency in the corticosterone-induced pheochromacytoma 12 (PC12) cells. Methods: PC12 cells were treated with $200 \mu \mathrm{M}$ of corticosterone in the absence or presence of different concentrations of RES for $24 \mathrm{~h}$. Then, cell viability was measured by Cell Counting Kit- 8 assay. Apoptosis of PC12 cells was measured by Annexin V-FITC and Propidium iodide (PI) labelling. The expression of apoptosis-related proteins including $\mathrm{Bax}, \mathrm{Bcl}-2$, caspase- 3 was determined by western blotting. Results: The results showed that treatment with $200 \mu \mathrm{M}$ of corticosterone induced cytotoxicity in PC12 cells. However, different concentrations of RES $(2.5 \mu \mathrm{mol} / \mathrm{L}, 5 \mu \mathrm{mol} / \mathrm{L}$ and $10 \mu \mathrm{mol} / \mathrm{L})$ significantly increased the cell viability, suppressed the apoptosis of PC12 cells, down-regulated Bax and caspase-3 protein expression, and up-regulated Bcl-2 protein expression, compared to the model group $(p<0.05)$. Conclusion: Resveratrol has a protective effect on corticosteroneinduced neurotoxicity in PC12 cells, which may be related to the apoptosis via inhibition of apoptosis-related proteins and displays the antidepressant-like effect.

Keywords - resveratrol PC12 cells • corticosterone $\cdot$ apoptosis $•$ neurotoxicity

\section{Introduction}

Depression is one of the most common mental disorders, more than 300 million people worldwide suffering from depression. Depression leads to a decline in social ability and causes severe burden [1,2]. The pathogenesis of depression has not been fully elucidated. Some acceptable mechanisms include the monoamine neurotransmitter hypothesis, the hypothalamic-pituitaryadrenal (HPA) axis activation hypothesis, nerve-inflammation hypothesis, cytokine hypothesis [3-5]. Antidepressant drugs such as serotonin reuptake inhibitors can inhibit the activation of HPA axis [6-7]. However, long-term use antidepressant can cause lots of side effects. The discovery of new antidepressants with high efficiency and low toxicity is one of the important research topics in psychopharmacological field. Resveratrol, known as trans-3,4,5-trihydroxy-stilbene, is a kind of biological polyphenols, mainly derived from peanuts, grapes and mulberry [8-11]. Researches have been shown that RES could improve depression behavior [12-16]. The mechanisms may associate with the regulation of brain derived neurotrophic fatcor, HPA axis, an increase of 5-HT, reduction of inflammatory factors, neurons protection [17-20].However, the exact mechanism is still unknown.

The PC12 cell line is a popular cell model which is common use in a variety of studies. It exerts typical neuron-like properties and produces glucocorticoid receptors [21]. It also has been shown that high concentrations of corticosterone can induce cellular damage of PC1 2 cells $[22,23]$. Further, the antidepressants have been demonstrated to protect against cytotoxicity induced by corticosterone in PC12 cells [24]. Research also showed that cytoprotective effect is a common action pathway for antidepressants [25].

Thurs, in the present study, PC12 cell line was first applied to investigate the neuroprotective effect of RES and its potential mechanisms.

\author{
Ye Zhang ${ }^{1,2}$, \\ Yun $\mathrm{He}^{3}$, \\ Ning Deng ${ }^{1}$ \\ Yan Chen ${ }^{4}$ \\ Jiecong Huang ${ }^{5}$ \\ Wei Xie ${ }^{1,6, *}$
}

School of Traditional Chinese Medicine, Southern Medical University, Guangzhou, Guangdong, 510515, China

'Department of Traditional Chinese Medicine, The Third People's Hospital of Yunnan Province, Kunming, Yunnan, 650011, China

${ }^{3}$ Department of Orthopedics, Calmett Hospital \& The First Hospital of Kunming, Kunming, Yunnan, 650224, China

${ }^{4}$ Normal Human Anatomy and Histological Embryology Department, Yunnan University of Traditional Chinese Medicine Kunming, Yunnan, 650500, China

${ }^{5}$ Department of Encephalopathy, Guangzhou Conghua Hospital of Traditional Chinese Medicine, Guangzhou, Guangdong, 510900 China

${ }^{6}$ Department of Traditional Chinese Medicine, Nanfang Hospital, Southern Medical University, Guangzhou, Guangdong, 510515, China

Received 12 November 2018 accepted 22 July 2019

\section{Materials and Methods}

\section{PC12 cell line}

Rat adrenal medullary pheochromocytoma PC12 cell line was purchased from the cell resource center of Shanghai Institutes for Biological Sciences.

\section{Drugs and reagents}

Resveratrol (Beijing Solarbio CO., Ltd, China); Corticosterone (Dalian Meilun Biotechnology CO., Ltd, China); Polyclonal rabbit antibodies (Bax, Bcl-2, caspase-3) (Santa Cruz Biotechnology CO., Ltd, CA); Cell Counting Kit8 (CCK-8) reagent (Colleague, Japan); Flow cell apoptosis assay kit (Nanjing Vazyme CO., Ltd, China).

\section{Cell culture and treatment}

PC12 cells were maintained in DMEM/ F12 medium supplemented with $10 \%$ fetal bovine serum, $200 \mathrm{U} / \mathrm{mL}$ penicillin and 100 $\mu \mathrm{g} / \mathrm{mL}$ streptomycin. A recent study showed significant differences in reproducibility can be 
conferred when variable passage numbers of PC12 cells are used [26]. The 2-5 generations of cells in good culture condition was chosen to use in our study. Cells were seeded at a density of $2 \times 10^{4}$ cells/well in 96 - well culture plates or cultured in cell bottle at a density of $2 \times 10^{4} / \mathrm{mL}$ in a humidified atmosphere containing $5 \% \mathrm{CO}_{2}$ atmosphere at $37^{\circ} \mathrm{C}$ for $24 \mathrm{~h}$. The cells were divided into six groups: Control group, where PC12 cells were not treated; Model group, where PC12 cells were treated with $200 \mu \mathrm{M}$ corticosterone; and RES groups with different concentrations of RES $(1 \mu \mathrm{M}, 2.5 \mu \mathrm{M}, 5 \mu \mathrm{M}, 10$ $\mu \mathrm{M})$. Cells in each group were cultured for $24 \mathrm{~h}$.

\section{Cell viability assay}

Cell Counting Kit-8 (CCK-8) assay was used to measure cell viability. Cells in each group were seeded in 96-well plates, and followed by incubation of this cells with different concentrations of RES for $24 \mathrm{~h}$ and then the medium was replaced with CCK-8 reagent 10ul/ well at $37^{\circ} \mathrm{C}$ and incubated for $4 \mathrm{~h}$. The optical density of each well was measured using a microplate reader to determine absorbance (A). Each sample was set in 4 multiple wells and the mean value was calculated. The blank control group was the well with only the culture medium. The survival rate of $\mathrm{PC} 12$ cells (\%) was calculated: ( $A$ in the experimental group - $A$ in the blank control group)/ ( $A$ in the control group - A value in the blank control group) $\times 100 \%$.

\section{Apoptosis Detection}

The cells in each group were washed twice with $0.1 \mathrm{M}$ PBS, digested with $0.25 \%$ trypsin, and then washed by ice-cold PBS, centrifuged at $300 \mathrm{~g}$ at $4{ }^{\circ} \mathrm{C}$ for $5 \mathrm{~min}$. According to the instruction, single cell suspension liquid was obtained and resuspended with $100 \mu$ l Binding buffer and constantly shaken for $15 \mathrm{sec}$. Then, $5 \mu$ Annexin V-FITC and $5 \mu$ Propidium iodide (PI) was added and incubated at $4{ }^{\circ} \mathrm{C}$ for 30 mins in dark. Finally, the cells were incubated with $400 \mu \mathrm{l}$ Binding buffer for $1 \mathrm{~h}$. The flow cytometry was used to detect the apoptosis at a wavelength of $488 \mathrm{~nm}$. Cell apoptosis rate was calculated.

\section{Western blot analysis}

Western blot was used to detect the expression of apoptosis-related proteins: $\mathrm{Bax}, \mathrm{Bcl}-2$ and caspase3. Cells in each group after $0.25 \%$ trypsin digestion were centrifuged at $1000 \mathrm{rpm}$ for $5 \mathrm{~min}$ at $4^{\circ} \mathrm{C}$ and washed with PBS three times. Then, Cells were lysed with ice-cold cell

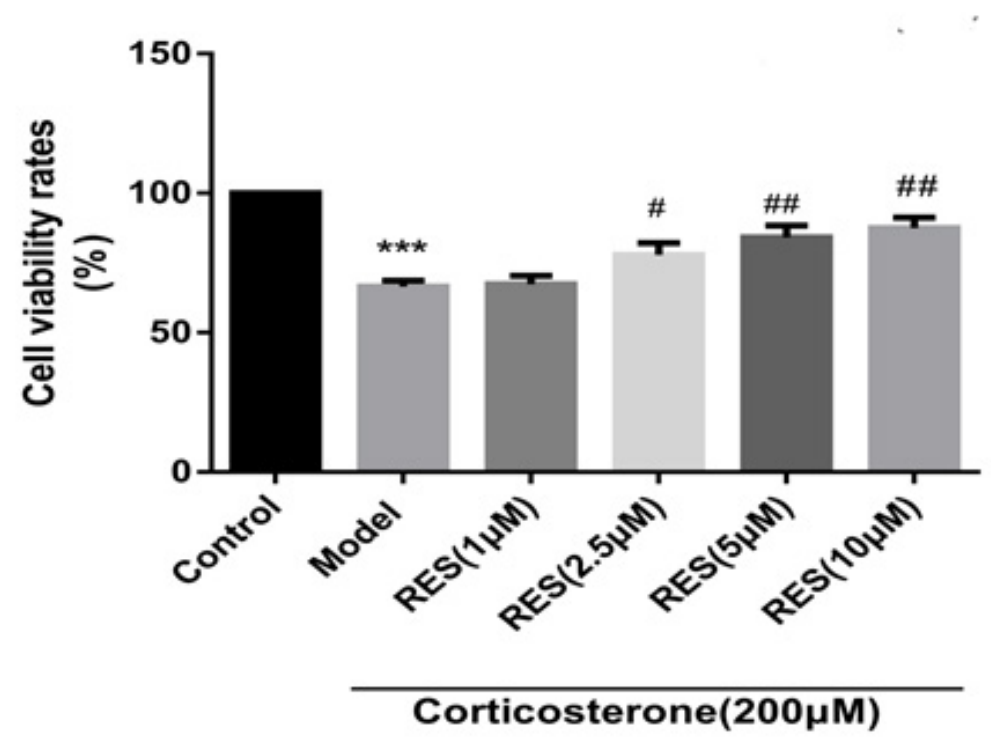

Fig. 1 Effects of RES on cell viability rates in corticosterone-induced PC12 cells. The control group is treated without corticosterone and the model group was treated with $200 \mu \mathrm{M}$ corticosterone on PC12 cells. Data are presented as means \pm SD $(n=6)$. ${ }^{* *} p<0.01$ vs control group. RES groups are of different concentrations of RES $(1 \mu M$, $2.5 \mu \mathrm{M}, 5 \mu \mathrm{M}, 10 \mu \mathrm{M}$ ) on corticosterone-induced PC12 cells. Data are presented as a percentage of model and the results were expressed as the means $\pm \mathrm{SD}(\mathrm{n}=6)$. \#p $<0.05$ and \#\# $p<0.01$ vs model group

lysis buffer and centrifuged at $4{ }^{\circ} \mathrm{C}$ for $15 \mathrm{~min}$. Protein concentration was measured using a BCA kit. Equal amounts $(20 \mu \mathrm{g})$ of protein were electrophoresed on SDS acrylamide gels and then proteins were transferred to nitrocellulose membranes. 5\% skim milk in TBST buffer was used to block the non-specific binding. The membranes were incubated with corresponding primary antibodies overnight at $4{ }^{\circ} \mathrm{C}$ and then incubated with IgG secondary antibodies for $1 \mathrm{~h}$ at room temperature. Finally, the detection was performed using enhanced chemiluminescence. The bands were quantified using Quantity One imaging software. The ratio between the target band and the reference $\beta$-actin was used as a semi-quantitative result.

\section{Statistical analysis}

SPSS 20.0 statistical analysis software package was used to process the data. Data were expressed as means $\pm S D$, and multiple group comparisons were performed using t-test. $p<$ 0.05 was considered to indicate a statistically significant difference.

\section{Results}

\section{RES protects against the cytotoxicity of corticosterone- induced PC12 cells}

Differentiated PC12 cells were treated with $200 \mu \mathrm{M}$ of corticosterone in the absence or presence of different concentrations of RES for $24 \mathrm{~h}$. Subsequently, the cell viability was measure by a CCK assay. As shown in figure 1 , the cell survival rate is $65 \%$ of the model group which significantly decreased compared to the control group $(p<0.01)$. Compared to the model group, the cell survival rates of different concentrations of RES $(2.5,5$ and $10 \mu \mathrm{mol} / \mathrm{L})$ are $73.4 \pm 0.29 \%, 78.9 \pm 0.33 \%$ and $82.6 \pm 0.23$ $\%$, respectively, which are significantly increased $(p<0.05)$. However, the cell survival rate $(66.9 \pm 0.24 \%)$ of $1 \mu \mathrm{mol} / \mathrm{L}$ of RES has no significant difference $(p>0.05)$.

\section{RES attenuates cell apoptosis of corticosterone-induced PC12 cells} In terms of exploring the effects of RES on cell apoptosis in corticosterone-induced PC12 cells, Annexin V- FITC, PI and flow cytometry 
were used. As shown in figure 2 (A, B and C), the ratio of early apoptotic cells (Annexin $\mathrm{V}+$ / $\mathrm{PI}-$ ) and late apoptotic cells (Annexin $\mathrm{V}+/ \mathrm{PI}+$ ) in the model group increased to $16.7 \pm 0.52 \%$ and $18.5 \pm 0.74 \%$, respectively compared with the control group $(p<0.05)$. However, $2.5 \mu \mathrm{mol} / \mathrm{L}$ RES, decreased the early and late apoptosis rate to $15.27 \pm 0.39 \%$ and $6.8 \pm 0.42 \%, 5 \mu \mathrm{mol} / \mathrm{L}$ RES decreased to $12.7 \pm 0.33 \%$ and $5.61 \pm 0.43 \%$, $10 \mu \mathrm{mol} / \mathrm{L}$ RES dropped to $15.73 \pm 0.57 \%$ and $6.38 \pm 0.24 \%$, respectively $(p<0.05)$.

\section{RES changes the expression}

of Bcl-2, Bax and caspase- 3 of corticosterone-induced PC12 cells

For further research, the effects of RES on the expression of apoptosis-related proteins were measured. As shown in figure 3, compared to the control group. the expression of Bax and caspase- 3 in the model group significantly increased $(p<0.01)$ while $\mathrm{Bcl}-2$ expression reduced $(p<0.01)$. Bax and caspase- 3 expression of RES groups was down-regulated, while $\mathrm{Bcl}-2$ expression increased $(p<0.05)$.

\section{Discussion}

Depression is a mood disorder characterized by persistently feelings of low self-esteem, pessimism, and despair. About $15 \%$ of patients with depression commit suicide. The pathogenesis of depression has not been fully elucidated until now. The currently accepted mechanisms include a mono amine neurotransmitter hypothesis, the HPA axis activation hypothesis, nerve-inflammation hypothesis, cytokine hypothesis, neural plasticity reduction hypothesis, the limbic system loop hypothesis, etc. The activation of HPA axis hypothesis considered that patients with depression activated pathological HPA axis excessively, which was closely associated with suicidal behavior of depression[27]. Antidepressant drugs such as serotonin reuptake inhibitors can inhibit the activation of HPA axis[28-29].

In the study, it is found that RES increased the cell viability, reduced apoptosis, and relieved the neurotoxicity of corticosterone on PC12 cells. We investigated the expression of three apoptosis-related proteins including $\mathrm{Bcl}$ 2, Bax and caspase-3. Apoptosis is associated with the activation of a genetic program in which apoptosis effector genes promotes cell death. This is regulated by the action of the $\mathrm{Bcl}-2$ family of proteins, which includes anti- and pro-apoptotic members such as $\mathrm{BCl}-$ 2 and Bax. It was reported that $\mathrm{BCl}-2$ binds to the mitochondrial membrane and undergoes competitive binding with Bax, forming the $\mathrm{BCl}-2 / \mathrm{Bax}$ heterodimer, thereby, leading to inhibiting apoptosis. As a pro-apoptotic molecule, Bax can be combined into a Bax-Bax homodimer to form the composition of the mitochondrial membrane permeable channels, through which cytochrome $\mathrm{C}$ can transfer from

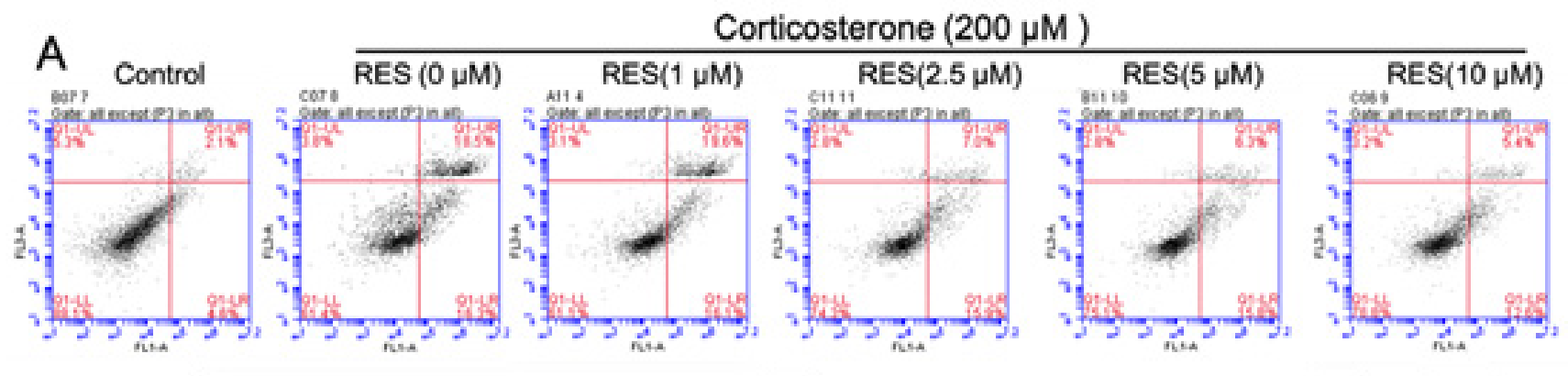

B

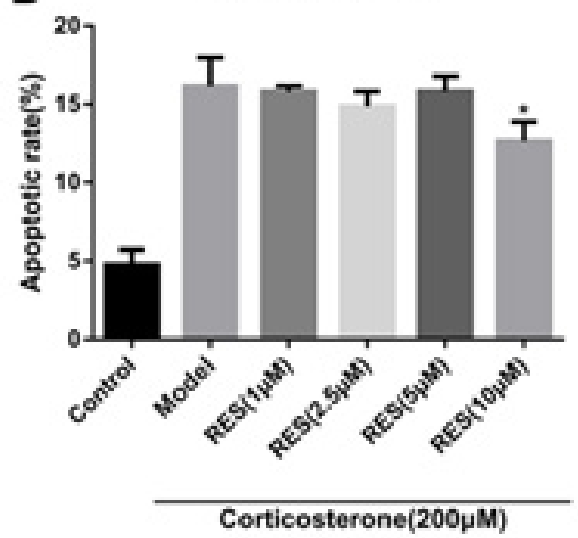

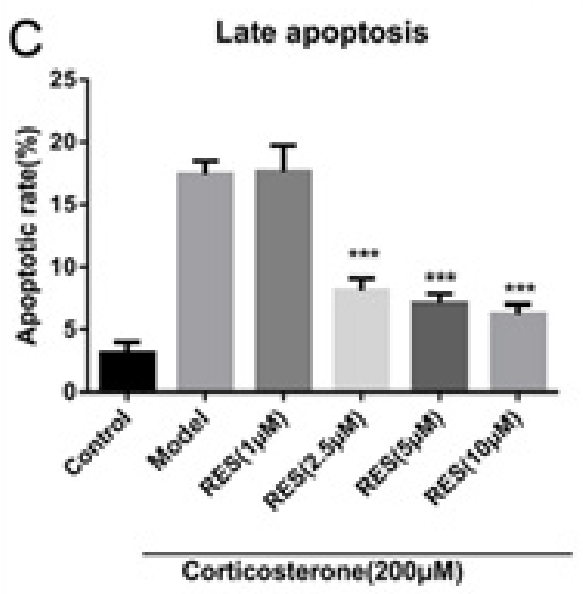

Fig. 2 Effects of RES on apoptosis rate in corticosterone-induced PC12 cells. The effect of RES on corticosterone-induced PC12 cell apoptosis based on flow cytometry analyses. The proportion (\%) of cells in each quadrant is shown. Lower left quadrant (absence of both markers) indicates viable cells; upper left quadrant [propidium iodide (PI) positive] indicates cellular necrosis; upper right quadrant (Annexin V positive and PI positive) indicates late-stage apoptosis or cellular necrosis; lower right quadrant (Annexin $V$ positive) indicates early-stage apoptosis. (B) Analysis of early-stage apoptosis, $(n=3)$. (C) Analysis of late-stage apoptosis, $(n=3)$. Data are expressed as a percentage of the control and the results are expressed as the means \pm SD. ${ }^{*} p<0.05$ and ${ }^{* * *} p<0.01$ vs model group. 


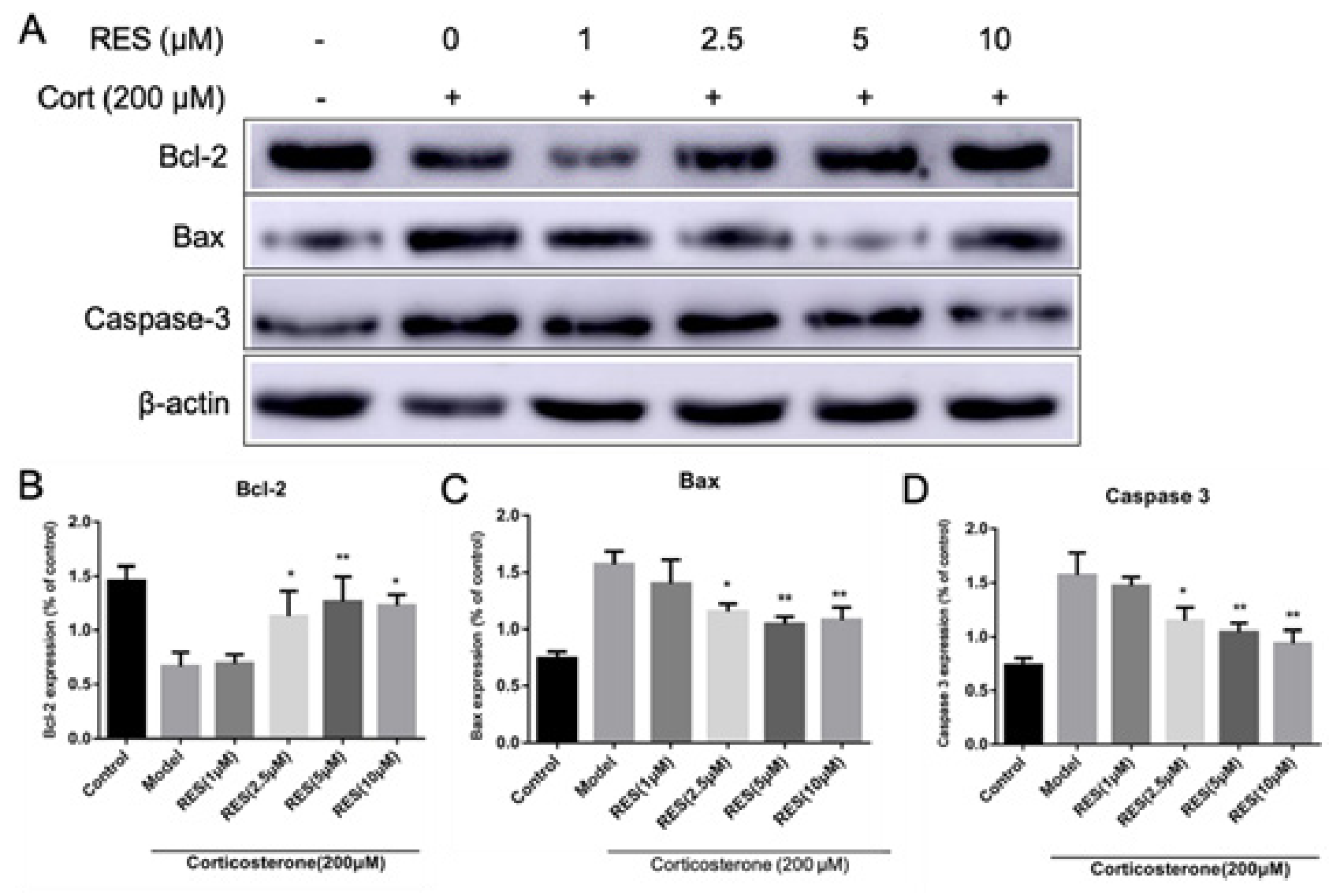

Fig. 3 Effects of RES on the expression of BCl-2, Bax and caspase-3 in corticosterone-induced PC12 cells. The model group was treated with $200 \mu \mathrm{M}$ corticosterone(Cort) on PC12 cells. RES groups are of different concentrations of RES $(1 \mu \mathrm{M}, 2.5 \mu \mathrm{M}, 5 \mu \mathrm{M}, 10 \mu \mathrm{M})$ on corticosterone-induced PC12 cells. Figure A: Western blot analysis; Figure B, C, $\mathrm{D}$ : Quantification of Bcl-2, Bax and caspase-3 expression were presented in bar graphs as the fold-increase, respectively.Data are as means $\pm S D(n=5) .{ }^{*} p<0.05$ and ${ }^{* *} p<$ 0.01 vs. model group.

mitochondria into cytoplasm which activate the caspase-related apoptosis cascade, resulting in mitochondrial-dependent apoptosis [30-33].

In order to further explore the molecular mechanism of RES in inhibiting corticosteroneinduced PC12 cell apoptosis, Bcl-2, Bax and caspase-3 proteins were detected by western blot in this study. The results showed that the concentrations of resveratrol range from 2.5 to $10 \mu \mathrm{mol} / \mathrm{L}$ inhibit apoptosis, increase $\mathrm{Bcl}-2$ protein expression, reduce Bax and Caspase 3 protein expression, which indicated that the regulation of RES on neuron apoptosis is mainly by increasing the ratio of $\mathrm{BCl}-2$ / $\mathrm{Bax}$ and inhibiting the activation of Caspase pathway.

We investigate the potential cytoprotective mechanism of RES. As a small molecule, RES is expected to pass the plasma membrane and accumulate within cells. When PC12 cells were stimulated by corticosterone, a large amount of reactive oxygen species (ROS) was produced. These excessive ROS would damage the mitochondria and cytomembrane, leading to apoptosis. Due to the antioxidant effect, RES suppressed oxidative stress, reduced the content of ROS. Moreover, we also found that RES could inhibit mitochondrial apoptotic pathways by reducing Bax and caspase-3 expression and increasing $\mathrm{Bcl}-2$ expression. The results of our study showed that RES is closely related to mitochondrial pathway, but whether it is associated with other regulation pathways still needs further investigations.

In the study, we first demonstrated that RES exerts neuroprotective effect in the corticosterone-induced $\mathrm{PC} 12$ cells and its mechanism may be related to the apoptosisrelated proteins.

\section{Acknowledgments}

This work was supported by the National Natural Science Foundation of China (81873158).

The authors are grateful for the excellent technical assistance provided by Prof.Di Lu form Kunming Medical University. 
1] Smith K. Mental health: a world of depression. Nature. Nov 13 2014;515(7526):181.

[2] Murray CJ, Lopez AD. Evidence-based health policy--lessons from the Global Burden of Disease Study. Science (New York, N.Y.). Nov 1 1996;274(5288):740-743.

[3] Aihara M, Ida I, Yuuki N, et al. HPA axis dysfunction in unmedicated major depressive disorder and its normalization by pharmacotherapy correlates with alteration of neural activity in prefrontal cortex and limbic/paralimbic regions. Psychiatry research. Aug 15 2007;155(3):245-256.

[4] Murray F, Smith DW, Hutson PH. Chronic low dose corticosterone exposure decreased hippocampal cell proliferation, volume and induced anxiety and depression like behaviours in mice. European journal of pharmacology. Mar 31 2008;583(1):115-127.

[5] Dean J, Keshavan M. The neurobiology of depression: An integrated view. Asian journal of psychiatry. Jun 2017;27:101-111.

[6] Carpenter LL, Tyrka AR, Lee JK, Tracy AP, Wilkinson CW, Price LH. A placebo-controlled study of sertraline's effect on cortisol response to the dexamethasone/corticotropin-releasing hormone test in healthy adults. Psychopharmacology. Nov 2011;218(2):371-379.

[7] Paslakis G, Heuser I, Schweiger U, Deuschle M. A single DEX/CRH test in male drug-free depressed patients is associated with the clinical response to treatment with fluoxetine. Journal of psychiatric research. Dec 2010;44(16):1154-1157.

[8] Liu MH, Yuan C, He J, et al. Resveratrol protects PC12 cells from high glucose-induced neurotoxicity via PI3K/Akt/FoxO3a pathway. Cellular and molecular neurobiology. May 2015;35(4):513-522.

[9] Kinarivala N, Shah K, Abbruscato TJ, Trippier PC. Passage Variation of PC12 Cells Results in Inconsistent Susceptibility to Externally Induced Apoptosis. ACS chemical neuroscience. Jan 18 2017;8(1):82-88.

[10] Hui Y, Chengyong T, Cheng L, Haixia H, Yuanda Z, Weihua Y. Resveratrol Attenuates the Cytotoxicity Induced by Amyloid-beta1-42 in PC12 Cells by Upregulating Heme Oxygenase- 1 via the PI3K/Akt/Nrf2 Pathway. Neurochemical research. Feb 2018;43(2):297-305.

[11] Wang H, Jiang T, Li W, Gao N, Zhang T. Resveratrol attenuates oxidative damage through activating mitophagy in an in vitro model of Alzheimer's disease. Toxicology letters. Jan 5 2018;282:100-108.

[12] Wang Z, Gu J, Wang X, et al. Antidepressant-like activity of resveratrol treatment in the forced swim test and tail suspension test in mice: the HPA axis, BDNF expression and phosphorylation of ERK. Pharmacology, biochemistry, and behaviour. Nov 2013;112:104-110.

[13] Liu D, Zhang Q, Gu J, et al. Resveratrol prevents impaired cognition induced by chronic unpredictable mild stress in rats. Progress in neuro-psychopharmacology \& biological psychiatry. Mar 3 2014;49:2129.

[14] Ge JF, Peng L, Cheng JQ, et al. Antidepressant-like effect of resveratrol: involvement of antioxidant effect and peripheral regulation on HPA axis. Pharmacology, biochemistry, and behaviour. Dec 2013;114115:64-69.
[15] Liu D, Xie K, Yang X, et al. Resveratrol reverses the effects of chronic unpredictable mild stress on behaviour, serum corticosterone levels and BDNF expression in rats. Behavioural brain research. May 1 2014;264:9-16.

[16] Ali SH, Madhana RM, K VA, et al. Resveratrol ameliorates depressivelike behaviour in repeated corticosterone-induced depression in mice. Steroids. Sep 2015;101:37-42.

[17] Ge JF, Xu YY, Qin G, Cheng JQ, Chen FH. Resveratrol Ameliorates the Anxiety- and Depression-Like Behaviour of Subclinical Hypothyroidism Rat: Possible Involvement of the HPT Axis, HPA Axis, and Wnt/beta-Catenin Pathway. Frontiers in endocrinology. 2016;7:44.

[18] Yang XH, Song SQ, Xu Y. Resveratrol ameliorates chronic unpredictable mild stress-induced depression-like behaviour: involvement of the HPA axis, inflammatory markers, BDNF, and Wnt/ beta-catenin pathway in rats. Neuropsychiatric disease and treatment. 2017;13:2727-2736.

[19] de Oliveira MR, Chenet AL, Duarte AR, Scaini G, Quevedo J. Molecular Mechanisms Underlying the Anti-depressant Effects of Resveratrol: a Review. Molecular neurobiology. Jun 2018;55(6):4543-4559.

[20] Wang Lipeng, Gao Zhaobing. Recent advances in the study on neuroprotection effects of resveratrol. Chinese Bulletin of Life Sciences. 2013, 25(6): 566-573.

[21] Li ZY, Guo Z, Liu YM, et al. Neuroprotective effects of total Saikosaponins of Bupleurum yinchowense on corticosterone-induced apoptosis in PC12 cells. Journal of Ethnopharmacology. Jul 30 2013;148(3):794-803.

[22] Anderson DJ, Michelsohn A. Role of glucocorticoids in the chromaffin-neuron developmental decision. International journal of developmental neuroscience : the official journal of the International Society for Developmental Neuroscience. 1989;7(5):475-487.

[23] Li YF, Liu YQ, Huang WC, Luo ZP. Cytoprotective effect is one of common action pathways for antidepressants. Acta pharmacologica Sinica. Oct 2003;24(10):996-1000.

[24] Zhang $\mathrm{H}$, Zheng $\mathrm{H}$, Zhao G, et al. Metabolomic study of corticosteroneinduced cytotoxicity in PC12 cells by ultra performance liquid chromatography-quadrupole/time-of-flight mass spectrometry. Molecular bioSystems. Mar 2016;12(3):902-913.

[25] LI Yun-Feng, LIU Yan-Qin, HUANG Wen-Chao, et al. Cytoprotective effect is one of common action pathways for antidepressants. Acta Pharmacol Sin 2003 Oct; 24 (10): 996-1000.

[26] Kinarivala N, Shah K, Abbruscato TJ, Trippier PC. Passage Variation of PC12 Cells Results in Inconsistent Susceptibility to Externally Induced Apoptosis. ACS chemical neuroscience. Jan 18 2017;8(1):82-88.

[27] Dean J, Keshavan M. The neurobiology of depression: An integrated view. Asian journal of psychiatry. Jun 2017;27:101-111.

[28] Carpenter LL, Tyrka AR, Lee JK, Tracy AP, Wilkinson CW, Price LH. A placebo-controlled study of sertraline's effect on cortisol response to the dexamethasone/corticotropin-releasing hormone test in healthy adults. Psychopharmacology. Nov 2011;218(2):371-379. 
[29] Paslakis G, Heuser I, Schweiger U, Deuschle M. A single DEX/CRH test in male drug-free depressed patients is associated with the clinical response to treatment with fluoxetine. Journal of psychiatric research. Dec 2010;44(16):1154-1157.

[30] Kosten TA, Galloway MP, Duman RS, Russell DS, D'Sa C. Repeated unpredictable stress and antidepressants differentially regulate expression of the bcl-2 family of apoptotic genes in rat cortical, hippocampal, and limbic brain structures. Neuropsychopharmacology: official publication of the American College of Neuropsychopharmacology. Jun 2008;33(7):1545-1558.
[31] Tobe I, Ishida Y, Tanaka M, Endoh H, Fujioka T, Nakamura S. Effects of repeated maternal stress on FOS expression in the hypothalamic paraventricular nucleus of fetal rats. Neuroscience. 2005;134(2):387-395.

[32] Sattler R, Tymianski M. Molecular mechanisms of glutamate receptormediated excitotoxic neuronal cell death. Molecular neurobiology. Aug-Dec 2001;24(1-3):107-129.

[33] Kowaltowski AJ, Fenton RG, Fiskum G. Bcl-2 family proteins regulate mitochondrial reactive oxygen production and protect against oxidative stress. Free radical biology \& medicine. Dec 1 2004;37(11):1845-1853. 